\title{
Research background, content and route of geological environment survey and evaluation for typical metal mines in Yunnan, China
}

\author{
Xian Feng CHENG ${ }^{1,2 a}$, Jun $\mathrm{XU}^{2}$, Wu Fu QI ${ }^{2}$, Qian Rui HUANG ${ }^{2}$, Yi ZHENG ${ }^{2}$, Ping HE ${ }^{3}$ \\ ${ }^{1}$ China University of Geosciences, Beijing 100083, China; \\ 2 Yunnan Land and Resources Vocational College, Yunnan Kunming 652501, China; \\ ${ }^{3}$ Kunming University, Yunnan Kunming 652501, China
}

\begin{abstract}
Based on present condition analysis of survey and assessment of geological environment of mines in China, mining geo-environmental problems in Yunnan Province were discussed in this paper. Then, main content, critical technology and research approach of typical mines were given. The objective is to be helpful for technological means of survey and assessment of metal mines' geological environment.

Key words. Metal mines; Geological environment; Survey; assessment; Yunnan
\end{abstract}

\section{Introduction}

Mineral resources is the important material basis for the human survival and development.China is a great power with a long history of mining. However, the extensive development activity of mineral resources has caused many environmental geological problems in mines while protecting the national economy development needs and creating huge economic benefits. Some of the problems pose a threat to the mining area and the surrounding people's life and property safety and restrict the sustainable development of mining industry itself. The large-scale and high strength of mineral resources development has become the most active geological force and a "catalyst" to influence and change the geological environment of mining areas (figure 1). So, the environmental geological problems caused by the mineral resources exploitation need to be solved urgently. In the future, it is the inevitable choice to build resourceconserving, environmental friendly and green ecological mines.

As one of the main environmental geological research methods and approaches, mine geological environment survey and evaluation is six-in-one geological work integrating practicability, fundamentality, commonweal, perspectiveness (to formulate mine geological environment protection plans and prevention scheme), intersectionality (comprehensive application of multidisciplinary) and systematicness (resource defacement, geologic hazards and environmental pollution). So, the work has been playing an increasing important role in the mine environment protection [4] .

In the paper, the work of mine geological environment survey and evaluation of the present situation in China was reviewed, and the mine environmental geological problems in Yunnan province was summarized. On the basis, it discussed the main contents, key technologies and research approaches of the typical metal mine geological environment investigation and evaluation in Yunnan. The purpose is to explore technical path of the typical metal mine geological environment survey and evaluation and provide reference for carrying out the next step work.

\section{Current situation of mine geological environment survey and evaluation in China}

It began to carry out the mine geological environment survey work systematically in the late $1990 \mathrm{~s}$ in China. Especially, a lot of work in mine environmental protection has been done since the foundation of the Ministry of Land and Resources, adhering to the principle of "protection in the development, development in the protection".

China Geological Survey deployed mine geological environment survey designedly in the great survey for the land and resources in 2000, marking the start of publicwelfare and systematic mine geological environment survey in China. In 2002, China geological survey launched the national mine geological environment survey and evaluation program by the province as a unit, and it is the first time to know the real situation of geological environmental problems for all mines systematically and comprehensively. After five years of efforts, 113149 mines were investigated, involving 193 mine types. The survey found out the current situation of the mine geological environment and main environmental geological problems and the damages. It got A series of

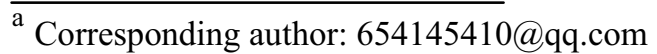


achievements, such as "the mine geological environment investigation in China" by Jin-de Zhang, etc. (2009)[5] , "Survey and assessment on environmental geology problems of mine in northwest China" by You-ning Xu (2006) [6] and "Regional characteristics of mineral resources and mining environmental geological problems in Central south China" by Jin-hui Cai (2009)[7] .

The survey results was the basis to establish relevant laws, regulations and institution. In 2005, "the notice of the provincial planning and management work in mine environmental protection" was issued by the Ministry of Land and Resources the implementation. "Compiling code on the project of mining geo-environmental protection and integrated renovation" was issued in 2007 , then the governance standard for mining industry was revised in 2011. The mine geological environment protection and management institution of recovery program was established in 2009. In April 2010, the national mine geological environment protection and treatment planning (2009-2015) was promulgated formally. In 2013, Xi'an center of China geological survey accomplished the first national comprehensive evaluation map of Chinese mine environment investigation and research-"the mine environmental geological map (1/4 million) and the specification of China".

By the end of 2010, all kinds of mines damaged land area of 3.868 million hectares cumulatively in China. Pumping and dewatering due to mining activities influenced groundwater aquifer of mining area about 4.96 square kilometers. Mine drainage added up to 69.41 billion tons in 2010. Mineral resources development produced a large amount of waste gas and dust and seriously affected the atmospheric environment around the mining area, of which most serious coal and sulfur chemical mines. The solid waste generated by mining activities added up to burden of 41.14 billion tons. According to the new data, the Chinese mining industry induced 21932 geological disasters by the end of 2011 , caused a direct economic loss of about 33.53 billion yuan. Obviously, the mine geological environment protection and management work is still a long way in China.

The first round of the national mine geological environment survey and evaluation can't meet the needs of the national project planning and implementation, because of lack of time to carry out in accordance with the regional environmental geology survey specification, but the technical route-"previous information collection, primary to fill out a form investigation, combined with remote sensing investigation aided, field survey and verification of typical mine" [8].

One of the key problems was low accuracy in the investigation of mine geological environment status of "background"; the other was the lack of mine geological environment monitoring system, so the development of the mine environmental geological problems is not clear.Therefore, it is imperative to investigate major mines geological environment detailedly in China. Thus, 86 main mineral resources development zones (belts) (about 75 square kilometers) is carried out 1:50000 detailed investigation at present for current situation of geological environment, the main environmental geological problems and damage degree.

\section{Profile of the mine environmental geological problems in Yunnan Province}

\subsection{The mine environmental geological problems}

Known as the "kingdom of nonferrous metals", Yunnan province is rich in mineral resources.

9 kinds of mineral reserves rank first in China, such as lead, zinc, tin, phosphorus and so on. 12 kinds of mineral reserves are on the top three, such as platinum, germanium, diatomite, copper, antimony, nickel.

The potential economic value of proven reserves is about 3 trillion yuan, and mining industry is one of the five pillar industries in Yunnan province.

According to "the overall planning of the mineral resources in Yunnan province (2008-2015)", Yunnan will implement a number of mining development and major construction projects. But the planning also pointed out that one of the major problems existing in the development and utilization of the mine ecological environment is serious, with requirement of building a resource-conserving and environmental friendly mining industry.

Yunnan is one of provinces with the most complex and serious problems of the mine geological environment. According to 72 mining areas in 390 sampling evaluation on the quality of mine geological environment of mining enterprises, the results showed that the extremely serious accounted for $37.5 \%$, the serious accounted for $44.4 \%$, and the general accounted for $18.1 \%$. Obviously, the mine geologic environment in Yunnan province was bad. Mine environmental status in whole province at present is deteriorating into worse stage, and the environmental situation is not optimistic. Summing up, the main problems in mines in Yunnan can be divided into 3 types and 15 sub-types, causing a direct economic loss of 307.3074 million yuan and 1203 deaths (table 1) [9]. It has become an important issue of the province's economic and social sustainable development and harmonious development of man and nature to to rationally utilize mineral resources and effectively protect the ecological and geological environment [10].

Table 1 Table of the main mine geological environment problems in Yunnan province

\subsection{The important significance of geological environment survey and evaluation for typical metal mines}

Mine geological environment survey and evaluation in Yunnan province synchronized with the national work, and part of the work is at the forefront. Since the $1980 \mathrm{~s}$, some mining areas in Yunnan province have carried out geological environment investigation, such as "Yimen copper mine exploration and development influence of geological environment survey", "Jinshachang lead-zinc mine geological hazards survey in Yongshan Country", 
etc. The objects of research in this period were mainly hydrogeology, engineering geology and geological hazards, while the mine geological environment survey and evaluation work basically focused on the individual points. Since 1997, the former Yunnan Bureau of Geology and Mineral Resources successively arranged two investigation projects, namely "Mine environmental geological investigation in Yuxi district " and "Mine environmental geology survey in Wenshan Prefecture" .The work adopted methods of "the surface general survey, major mines survey and key environmental indicators monitoring, semi-quantitative evaluation of mine geological environment quality". Some working experience were figured out.

As a component of the typical mine geological environment assessment projects in China, the systemic work in Yunnan began in 2002. According to the characteristic of the complex geological conditions and mining enterprises distributing widely, the investigation was on the basis of predecessors' information collection, filling out a form on the surface of census and key point investigation for the typical mines. In 2003, the mine geological environment survey and evaluation report of Yunnan province was formed, through the comprehensive analysis of the data and the present conditions assessment. It provided the basic data of protection of geological environment, mine environmental comprehensive renovation, mine ecosystem restoration and reconstruction, the implementation of the mine geological environment monitoring. Due to the limitation of conditions at that time, it lacked in-depth study of the inducing factors, formation mechanism of the mine geological environment problems and regional geological environment background on the sensitivity of the mining activities and restriction function. The mine geological environment quality evaluation is given priority to with expert evaluation method, so it is difficult to ensure objectivity of evaluation results and hard to meet the needs of the mining recovery treatment project design and implementation. Therefore, it is still necessary to select typical mines to carry out detailed geological environment survey and evaluation work.

\section{Main content of geological environment survey and evaluation of representative metal mines in Yunnan}

\subsection{Geo-environment survey and sampling analysis of objective mines}

In accordance with technical manuals and documents spirit of "Detailed rules for the implementation of the mine geological environment survey technical requirements in China (amended)", "The mine geological environment protection and management planning in China(2009-2015)" and so on, it will be carried out field investigation and remote sensing mine environmental status of Gejiu tin mine, Dongchuan copper mine, Lanping lead-zinc mine, Dahongshan iron-copper mine and Beiya gold mine in case study. Ore, soil, air, water and organism will be sampled to make pointed references for detection and analysis.

(1) Specific content of the survey:

1) To find out the basic information of objective mines basically;

2) To find out the background of objective mines geological environment roughly;

3) To find out the mine geological environment problem type, distribution, scale and damage degree in detail, including:

- Influence on and damage to land source and geomorphologic landscape by mine exploitation;

- Influence on and damage to water source, especially groundwater system by mine exploitation;

- Type, scale, loss and damage of mining geological hazards;

- Mine environmental pollution problems : pollution of soil and water, destruction of ecological resources by solid waste(spoil,tailings)stacking and waste water(pit water,beneficiation wastewater 、 dump leaching wastewater etc.)discharge;

4) To investigate measures and effect of preventing and controlling mine geological environment

- Land rehabilitation and environmental construction efficiency of mines

- Comprehensive treatment and efficiency of mine wastewater and waste residue pollution

- Mine geological disaster prevention and control efficiency

(2)Sampling and analysis

To sample ore, tail sand, soil, air, water and biological materials systematically in mining area, and to sample some representative specimen outside the mining area for comparing the samples as the background value. To select some key sample for full analysis. Soil, air and water would be analyzed according to the mine environmental assessment needs; For different indicators selected according to the characteristics of different mining special analysis.Sample analysis focuses on heavy metals and related to the concentration of organic pollutants.

\subsection{Geological environment assessment of objective mines}

On the basis of the geological environment investigation and sample analysis, to do special evaluation and comprehensive evaluation of the objective mines. To evaluate heavy metal pollution of mine using the total analysis method, chemical speciation, biological method and so on. To evaluate the geological environment in mines using weighted score index comprehensive evaluation method, fuzzy mathematics comprehensive evaluation method, grey situation judgment method, environmental pollution index method and other methods respectively, and then to compare their advantages and disadvantages. To elect some for targeted evaluation methods of different kinds of mines. 


\subsection{The basic characteristics,impact assessment, prevention and control measures of objective mines geological disasters}

To summarize the essential features, damage characteristics and developmental rules on the basis of objective mines geological disasters survey. To select Dongchuan copper mine geological disasters carrying out researches of the environment impact assessment, dynamic changes and the prevention measures. To compare and analyze the forming conditions of the mine geological disasters according to the different types. To focus on the forming conditions of the mine debris flow.

Formation condition research of mine debris flow: to dissect Kafang debris flow in Gejiu mine area, Yinmingou and Heishangou debris flow in Dongchuan mine area, Nandagou debris flow in Lanping mine area in case study; according to the regional natural environment and geological conditions, to analyze and summarize typical mine debris flow gully watershed and channel characteristics using the method of remote sensing in combination with field investigation; according to field survey, to analyze and summarize typical mine debris flow gully sediment source condition, landform condition and water condition, etc., and combined with other aspects of judging the basic characteristics of the typical mine debris flow gully; according to the basic characteristics of the mine debris flow influence factors related to its starting, to establish the mine debris flow starting critical discrimination model; to analyze the starting mechanism of mine debris flow research finally .

\subsection{Distribution characteristics, migration mechanism and control measures of heavy metals and organic pollutants in objective mines}

On the basis of investigation and chemical pollution of heavy metals, to select 1-2 typical mines and find out distribution characteristics of heavy metals and organic pollutants in different environmental media (weathering profile typical ore deposits, mining pit, dump, tailings, surface water and groundwater, water sediment, sewage drainage sediment, river sediment, soil, air, etc.). to evaluate the pollution degree, the scope and the potential ecological harm of heavy metal in the soil of the different functional areas and water bodies using various methods.

\section{Research strategy}

It will be carried out investigation and evaluation of Gejiu tin mine, Dongchuan copper mine, Lanping leadzinc mine, Dahongshan iron-copper mine and Beiya gold mine in case study. To collect the former data of objective mines adequately. On the basis of remote sensing interpretation results, to carried out the field investigation, verification and sampling, supplemented by discussion, questionnaire and interview, etc; to do 1:10000 1:50000 geological mapping in key locations. To analyze, summarize the survey data, and figure out the actual materials and present status. To evaluate geological environment of mines. To dissect 1-2 target mines, focusing on the study of environmental impact assessment, and environmental pollution repair exploratory research on key technologies(figure 2).

\subsection{Data collection and analysis}

(1) to collect and clear up the technical data, such as the evaluation index system and mine geological environment assessment related technical specifications; (2) to collect the literature of science and technology domestic and overseas in recent 5 years; (3) to collect data of target mining natural geographical background, regional geological conditions, mineral resources and exploitation and utilization status, mining activities on the ecological environment influence, management information of mine geological environment restoration, the preliminary summary of the mine environmental geological problems.

\subsection{Remote sensing}

To deal with the image synthesis, integration, and enhance processing by getting different resolution of satellite remote sensing data and extract the mine geology environment information rapidly. To acquire the present situation of the mine geological environment, including quarry, tailings, dump, mine water, geological disasters (collapse, landslide, debris flow, ground subsidence, ground fissure, etc.), water and soil pollution, dust pollution, ecological destruction and so on. To make mine environmental geological problems of remote sensing interpretation map using visual interpretation, man-machine combination interpretation and computer automatic extraction according to the types and characteristics of remote sensing images.

\subsection{Field investigation and verification}

The contents include the basic situation of mine, occupation and destruction of land, land recovery governance, mining wastewater and effluent discharge, mine tailings solid waste, mine drainage effect of groundwater, the secondary geological disaster situation, etc. Adoption of 1/5 0000 topographic map as work base, combined with remote sensing interpretation chart. According to the above content item by item, to take photos of typical environment geological problems using a digital camera. If necessary, to attache sketches in accordance with the methods of field geological work. To verify remote sensing interpretation results by the chance of field investigation.

\subsection{Questionnaire investigation, interview and discussion}

The mine geological environment questionnaire form are distributed to the various mining enterprises, and filled in by the enterprise in accordance with the requirements for the questionnaire content one by one. Project professionals go into the first production line, and 
communicate with staff, and have an interview with the crowd near mines. Held by mining enterprises management and technical personnel to , to understand the status of mine geological environment and governance measures by mining enterprises management and technical personnel attending the symposium.

\section{Epilog}

Yunnan is a great province with mineral resources, biological resources and tourism resources, at the same time it is located in the upstream of six big rivers, namely Yangtze River, Zhujiang River, Lancangjiang River (Mekong River), Nujiang River (Salween River), Red River and Irrawaddy River. The benefit is not only in Yunnan province, but also producing good regional influence and international reputation by protecting the ecological environment of Yunnan.

As a prominent aspect of artificial environmental problems in Yunnan province, mine environmental geological problems should be solved urgently, and it has a long way for the protection and management work. It is an important basic, public welfare and social work to investigate and assess the mine geological environment. To make achievable mine environmental comprehensive renovation, mine ecosystem restoration and reconstruction scheme is beneficial to ease conflicts between tourism development and biological resources development and promote the sustainable, rapid and healthy development of the national economy.

\section{Acknowledgments}

Fund project: This study was supported by "Comprehensive utilization of resources and the evaluation of the mine environment survey of the typical metal mines in Yunnan province" (Grant No.[2013]1) and Department of Yunnan Education (Grant No.2015Y395).

\section{References}

1. Jun Wu. (1999). The mine environmental geological problems of Yunnan[J]. China geology, (4), 14-16.

2. Zhongli Tang et al. (2005). The mine geological environment problems and the countermeasures[J]. Journal of earth science and environment, 27 (2), 1-4.

3. You-ning Xu et al. (2011). Study on the difference of mine geo-environmental problem response to mineral resource exploitation :a case study about the mining areas in Tongguan and Daliuta of Shaanxi and Fuxin of Liaoning[J]. Journal of Earth Sciences and Environment, 33(1), 89-94.

4. You-ning Xu. (2008). Research status and prospects of mine geological environment survey[J]. Geological bulletin of China, 27 (8).

5. Jin-de Zhang, et al. (2009). The mine geological environment investigation in China [M]. Beijing: geology publishing house.

6. You-ning Xu. (2006) . Survey and assessment on environmental geology problems of mine in northwest China[M]. Beijing: geology publishing house.

7. Jin-hui CAI et al. (2009). Regional characteristics of mineral resources and mining environmental geological problems in Central south China [M]. Beijing: China university of geosciences press.

8. J D Zhang, D Q Zhang, L Tian.(2007). Methods of investigations and integrated assessments of the nationwide mine geo-environment[J]. Geological Bulletin of China, 26( 2) : 136- 140

9. Yu Huang. (2007). Research on the mine environmental geological problems and countermeasures in Yunnan province [D]. Kunming: Kunming university of science and technology.

10. Jun $\mathrm{Wu}$, et al. (2005). Mine environmental protection and renovation suggestions of Yunnan. China engineering science[J], 7, 397-400.

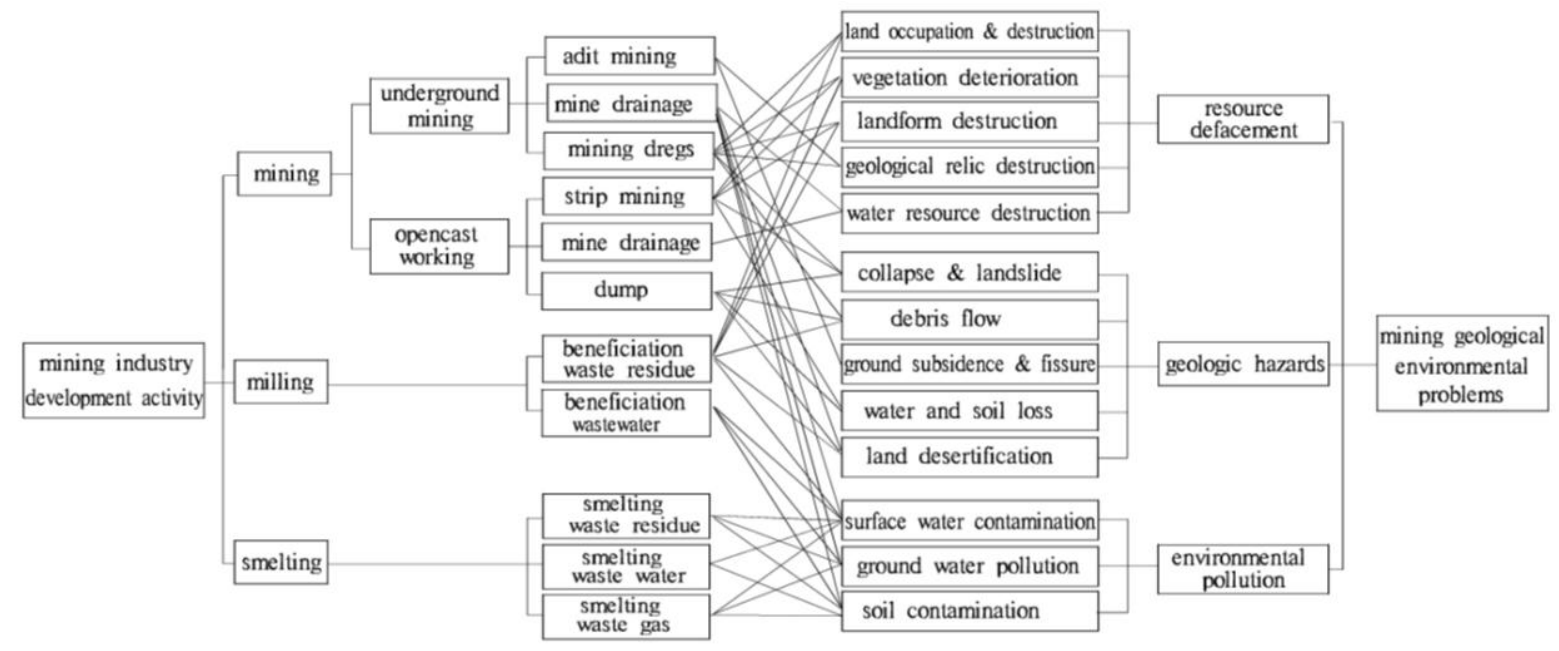

Figure 1. Schema of the relation between mine exploitation and environmental geological questions[1-3] 
Table 1 Table of the main mine geological environment problems in Yunnan province

\begin{tabular}{|c|c|c|c|c|}
\hline Types & number & $\begin{array}{c}\text { land occupation and } \\
\text { destruction( }(\mathrm{hm} 2)\end{array}$ & $\begin{array}{c}\text { economic losses } \\
\text { (million yuan) }\end{array}$ & $\begin{array}{c}\text { Deaths } \\
\text { (person) }\end{array}$ \\
\hline stope & & 30831.78 & & \\
\hline waste pile & & 2994.31 & & \\
\hline tailing pond & & 1128.22 & & \\
\hline Surface water contamination & 2000 & & \multirow{3}{*}{12} & \\
\hline groundwater pollution & 54 & & & \\
\hline soil contamination & 56 & & & \\
\hline collapse & 56 & 1038.84 & 8.06 & 135 \\
\hline landslide & 171 & 1124.52 & 133.0228 & 594 \\
\hline debris flow & 78 & 2491.8 & 69.6967 & 362 \\
\hline ground subsidence & 169 & 1101.52 & 62.8733 & 30 \\
\hline ground fissure & 179 & 1109.12 & 2.4476 & \\
\hline water inrush & 39 & & 11.077 & 30 \\
\hline springs unwatered & 100 & & & \\
\hline total & & 42004.37 & 307.3074 & 1203 \\
\hline
\end{tabular}

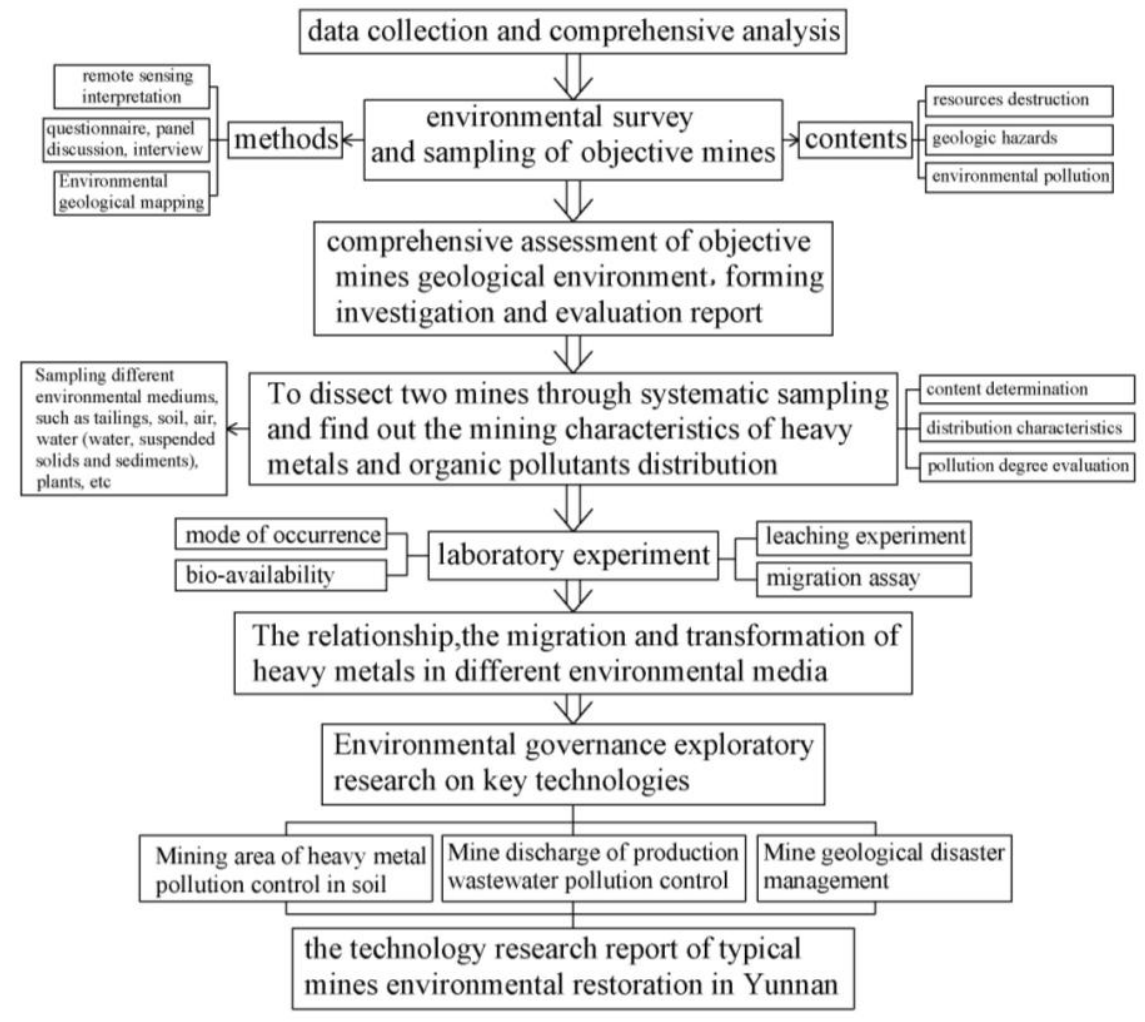

Figure 2. Technology Roadmapping of mine geological environment survey and assessment 